\title{
The highly overlapping actions of Lh signaling and Fsh signaling on zebrafish spermatogenesis
}

\author{
Yuxin Xie', Lianhe Chu', Yun Liu', Kathy W Y Sham', Jianzhen Li1,2 and \\ Christopher H K Cheng'
}

'School of Biomedical Sciences, The Chinese University of Hong Kong-Shandong University Joint Laboratory on Reproductive Genetics, The Chinese University of Hong Kong, Shatin, N.T., Hong Kong, China

${ }^{2}$ College of Life Sciences, Northwest Normal University, Lanzhou, China
Correspondence should be addressed to $\mathrm{J} \mathrm{Li}$ or $\mathrm{C} \mathrm{H} \mathrm{K} \mathrm{Cheng}$ Email

lijz1983@126.com or chkcheng@cuhk.edu.hk

\begin{abstract}
Gonadotropin signaling plays a pivotal role in the spermatogenesis of vertebrates, but exactly how gonadotropins regulate the process in non-mammalian species remains elusive. Using a gene knockout approach in zebrafish, we have previously demonstrated the non-canonical action of gonadotropin signaling on spermatogenesis by analyzing four single mutant lines ( $/ h b, I h r, f s h b$ and $f s h r$ ) and three double mutant lines (Ihb;fshb, $I h r ; f s h r$ and $f s h b ; / h r)$. In this study, we further investigated the actions of gonadotropins on the testis by establishing three other double-mutant zebrafish lines (Ihb;/hr, fshb;fshr and $/ h b ; f s h r$ ). All $/ h b ; / h r$ and $f s h b ; f s h r$ mutant males were fertile. Analysis on the gonadosomatic index and testicular histology in these $/ h b ; / h r$ and fshb;fshr mutants demonstrated that Lh signaling and Fsh signaling could functionally compensate each other in the testis. Intriguingly, it was found that the Ihb;fshr mutant male fish were also morphologically and histologically normal and functionally fertile, a phenomenon which could be explained by the cross-activation of Lhr by Fsh. We have demonstrated this cross-reactivity for the first time in zebrafish. Fsh was shown to activate Lhr using three different assay systems, in which Lh-Fshr activation was also confirmed. Taken together, we conclude that the action of Lh signaling and Fsh signaling is redundant in that either alone can support zebrafish spermatogenesis based on two observations. First, that either Lh signaling or Fsh signaling alone is sufficient to support male fertility. Second, that the two gonadotropin ligands could promiscuously activate both receptors. Apart from revealing the complexity of gonadotropin signaling in controlling male reproduction in zebrafish, this study also shed light toward a better understanding on the evolution of gonadotropin signaling in vertebrates from fish to mammals.
\end{abstract} Key Words

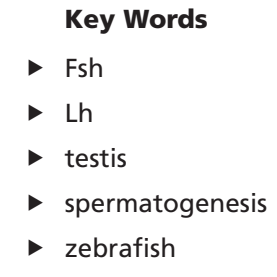

Journal of Endocrinology (2017) 234, 233-246

\section{Introduction}

Spermatogenesis is a complex and highly coordinated process for the continued production of a large number of spermatozoa. This process is highly conserved in vertebrates. The differentiating spermatogonia give rise to spermatocytes, which will then undergo meiosis resulting in haploid spermatids. Without further proliferation, mature motile spermatozoa emerging from the spermatids acquire the ability to fertilize. All these 
phases of spermatogenesis are under the strict control of gonadotropic hormone stimulation of their receptors in the testes (Pudney 1995, Schulz et al. 2010).

More specifically, both pituitary gonadotropins including luteinizing hormone (LH) and folliclestimulating hormone (FSH) exert their actions through binding to specific receptors in the testes, namely luteinizing hormone receptors (LHR) and folliclestimulating hormone receptor (FSHR). The structure, expression and function of gonadotropins and their receptors have been studied in a number of vertebrates (Fan \& Hendrickson 2005, Levavi-Sivan et al. 2010, Menon \& Menon 2012). Most of the information though comes from studies in mammals. Both LH and FSH regulate steroidogenesis and spermatogenesis by activating receptors expressed in Leydig cells (LHR) and Sertoli cells (FSHR), respectively. LH regulates the activity of Leydig cells by stimulating the synthesis and secretion of testosterone, while FSH regulates the function of Sertoli cells to support many aspects of sperm cell maturation (Themmen \& Huhtaniemi 2000, Huhtaniemi $\&$ Themmen 2005). However, how spermatogenesis is controlled by gonadotropin signaling in non-mammalian species is still largely unclear. In the primitive ancestral agnathan (jawless) vertebrates species such as Hagfish and lampreys, only one single gonadotrophin without specific Lh- or Fsh-like function and two receptors have been identified (Sower et al. 2009, Uchida et al. 2010, Nozaki 2013). During genome duplication from jawless teleost to jawed fish, two gonadotropins, namely Lh and Fsh akin to those in mammals, have emerged (Huhtaniemi 2015). Thus, studies on the actions of the more primitive gonadotropins and their receptors in fish are important in understanding the evolution of gonadotropin signaling in vertebrates. Comparing with the mammalian counterparts, differences on the structure, expression and regulation of fish gonadotropins have been reported. For example, marked divergence exists with regard to the specificity of the receptors toward the gonadotropins in fish. In mammals, interactions between the gonadotropins and their receptors are highly specific (Moyle et al. 1994), despite the fact that the equine chorionic gonadotropin (eCG) possessing equine LH activity has been reported to stimulate FSHR in several species (Camp et al. 1991, Cahoreau et al. 2015, Chakraborty \& Roy 2015, Wei et al. 2016). On the other hand, however, interactions between fish gonadotropins and their receptors appear to be less discriminatory. Fshr could be activated by both Fsh and Lh in a number of fish species (Yan et al. 1992, Vischer et al. 2003, Bogerd et al. 2005, Sambroni et al. 2007). However, reports about the activation of Lhr by Fsh are limited. Currently, it has only been reported in very few species such as rainbow trout (Sambroni et al. 2007). These differences imply functional differentiation of gonadotropins and their receptors from fish to mammals.

Recently, the emergence of gene knockout techniques provides the opportunity to dissect the in vivo gene functions in fish genetically (Huang et al. 2011, Chang et al. 2013, Hwang et al. 2013). Using an optimized TALENs platform established in our laboratory, we have successfully established the $l h b, f s h b, l h r, f s h r, l h b ; f s h b$, lhr;fshr and fshb;lhr mutant zebrafish lines (Liu et al. 2013, 2014, Chu et al. 2014, 2015). Using these genetic means, we have analyzed the functions of $f s h b, l h b, f s h r$ and $l h r$ in the testis of zebrafish. Intriguingly, all the single-gene mutant lines ( $f s h b, l h b, f s h r$ and $l h r$ ) and the double mutant line ( $f s h b ; l h r)$ are fertile. Both the structural integrity of the testis as revealed by histological examination and functional integrity as revealed by the fertilization rate are not affected. However, the double knockout mutant lines $l h b ; f s h b$ and $l h r ; f s h r$ all produce infertile males (Chu et al. 2014, 2015). These results suggest that gonadotropin signaling is essential for spermatogenesis and that Fsh signaling and Lh signaling exhibit some overlapping functions in controlling testicular function in zebrafish. To further unravel the complexity of the cross-activity between gonadotropins and their receptors in fish, we have established three additional double mutant zebrafish lines of $l h b ; l h r, f s h b ; f s h r$ and $l h b ; f s h r$ in the present study. Analysis of these mutant lines has led us to propose a more comprehensive model on how gonadotropins regulate spermatogenesis in zebrafish. The present study also contributes toward a better understanding of the evolution of gonadotropin signaling in vertebrates from fish to mammals.

\section{Materials and methods}

\section{Zebrafish husbandry}

Zebrafish used in this study were maintained at $28^{\circ} \mathrm{C}$ in the animal holding facilities of The Chinese University of Hong Kong. Fish were reared at a photoperiod of $16 \mathrm{~L} / 8 \mathrm{D}$ and fed twice a day with newly hatched brine shrimp (Brine Shrimp Direct, Ogden, UT, USA). All animal experiments were conducted following approval from the University Animal Experimentation Ethics Committee. 


\section{Targeted gene disruption by TALENs}

The procedures of generating the single-gene knockout mutants were performed as described, including the construction of pCS2-TALEN-ELD/KKR plasmids and microinjection (21). The mutations were ascertained by genomic PCR and sequencing (Supplementary Fig. 1, see section on supplementary data given at the end of this article). The TALENs-injected embryos were raised to adulthood and outcrossed with wild-type fish. F1 mutants were selected by sequencing, and self-crossed to obtain F2 generation. Part of the fin of each F2 zebrafish was cut for genotyping. Double gene knockout heterozygotes were obtained by crossing of two single-gene knockout heterozygotes (e.g. $l \mathrm{~h} b^{+-} ; f s h r^{+/-}$was generated from crossing $\mathrm{lhb}^{+/-}$with $f s h \mathrm{r}^{+-}$) (Chu et al. 2014, 2015). And these double knockout heterozygotes were then self-crossed to obtain the homozygous mutants (e.g. $l h b^{+--} ; f s h r^{+-}$self-crossed to obtain $\left.l h b^{-/-} ; f s h r^{--}\right)$. A similar strategy was adopted to obtain the other double knockout homozygous fish lines (Supplementary Fig. 2).

\section{Fertility test and sex ratio determination}

Male zebrafish of different genotypes were kept together with wild-type female fish in a 1 to 1 ratio as described (Chu et al. 2014). The number of healthy embryos was recorded to indicate successful fertilization, and the survival rate was calculated as the fertilization ratio. Individual mutant males of each genotype were tested every day for two weeks.

The determination of sex ratios of the offspring was from the mating of 3 different pairs of individuals. In order to determine the sex ratios, all offspring were raised to adulthood first, and then sexed by morphological observation followed by histological confirmation.

\section{Histological analysis of testes and immunohistochemistry}

Intact testes were carefully excised from adult male zebrafish (4-7 months post fertilization) after anesthetization and decapitation. After fixation in Bouin's fixative buffer (Sigma) overnight at $4^{\circ} \mathrm{C}$, testes were dehydrated and embedded in paraffin and sectioned at $3 \mu \mathrm{m}$ thickness. Slides were then stained with Harris hematoxylin and eosin (H\&E) (Sigma) for histological analysis. The staging of spermatogenesis was based on study by Leal and coworkers (Leal et al. 2009).
For immunohistochemistry, after antigen retrieval with $0.01 \mathrm{M}$ citrate buffer ( $\mathrm{pH}$ 6.0), the slides were washed with PTW (PBS, 0.1\% Tween) and blocked for $60 \mathrm{~min}$ in 5\% serum and 1\% BSA in PTW. Samples were incubated with the proliferation marker phosphohistone H3 (РHH3) (1:1500; Cell Signaling Technology) overnight at $4^{\circ} \mathrm{C}$ before being washed and probed with donkey anti-rabbit Alexa 555 (Invitrogen). Cell nuclei were visualized with 4'-6-diamidino-2-phenylindole (DAPI) (Invitrogen) counterstaining, and then mounted and photographed on a confocal microscope (Olympus FV1000, Japan) (Chu et al. 2014).

The number of each stage of sperms per unit area was counted using the Weibel's multipurpose test system (Mandarim-de-Lacerda 2003). Spermatogonia, spermatocytes, spermatids and spermatozoa cells could be clearly distinguished by H\&E staining, and sperm proliferation could be ascertained by PHH3 immunostaining.

\section{RNA isolation and quantitative real-time PCR}

Total RNA samples were extracted from the testes of zebrafish using TRIzol Reagent (Invitrogen). The amount and purity of the RNA were determined by spectrophotometry. Reverse transcription was performed using the PrimeScript RT Reagent Kit (TaKaRa) and quantitative real-time PCR was carried out on an ABI ViiA 7 Real-Time PCR System (ABI, Foster City, CA, USA) using the SYBR Green PCR Master Mix Kit (ABI) as Li and coworkers (Li et al. 2015). The full names of the genes and the primers used in this study are listed in Supplementary Table 1.

\section{Hormone assays and ELISA}

Blood samples were collected from the caudal vein of the fish as described in Pedroso and coworkers (Pedroso et al. 2012). Each fish could provide $5-10 \mu \mathrm{L}$ blood for the assays. After centrifugation at $5000 \mathrm{~g}$ for $20 \mathrm{~min}$ at $4^{\circ} \mathrm{C}$, the supernatants were isolated and purified with ethyl acetate by following the manufacturer's extraction instruction (Cayman Chemical). Competitive enzyme-linked immunosorbent assay (ELISA) kits were used to measure the serum levels of testosterone, 11-ketotestosterone (Cayman Chemical), and serum LH and follicle-stimulating hormone levels were measured by assay kits specific for the zebrafish hormones (MyBioSource, San Diego, CA, USA). All standards and samples were performed in triplicates. The sensitivity, specificity, intra- and inter-assay coefficients

Published by Bioscientifica Ltd 
of variation (CV) of the hormone assays according to the suppliers are listed in Supplementary Table 2.

\section{Cell culture, transfection and luciferase assays}

Chinese hamster ovary $(\mathrm{CHO})$ cells and African green monkey kidney fibroblast-like (COS-7) cells (ATCC) were used to perform receptor activity assays using transient transfection or stable transfection, respectively. The passage numbers of both cell lines were ranging from 20 to 30 . The cDNAs corresponding to the signal peptide and the entire mature zebrafish Lh or Fsh beta domain (117-residues for Lh and 112-residues for Fsh) followed by a 15-residue linker (GGGSGGGSGGGSGGG) and the mature zebrafish gonadotropin alpha domain (92 residues) were synthesized and cloned into pUC57 vector by GenScript (GenScript, Piscataway, NJ, USA). The coding regions of these two plasmids were subsequently subcloned into pcDNA3.1 by us via TA cloning strategy to generate the final pcDNA3.1-lh and pcDNA3.1-fsh expression plasmids. For construction of the pcDNA3.1-lhr and pcDNA3.1-fshr expression plasmids, the full coding regions of zebrafish $l h r$ and $f$ shr were amplified using the primers listed in Supplementary Table 1 and cloned into pcDNA3.1 by TA cloning.

For transient transfections, $\mathrm{CHO}$ cells were maintained in Ham's F-12K (Kaighn's) medium (Thermo Fisher Scientific) supplemented with $10 \%$ fetal bovine serum (FBS) and $1 \%$ penicillin and streptomycin (PS) and kept at $37^{\circ} \mathrm{C}$ with $5 \% \mathrm{CO}_{2}$. Cells were seeded at $5 \times 10^{4}$ cells per well on 24-well plates (Corning, Corelle, NY, USA) one day prior to transfection. Each well was transfected with $500 \mathrm{ng}$ of a cAMP-responsive reporter construct pCRE-Luc, 50 ng of a pRL-CMV vector containing the Renilla luciferase reporter gene, 200 ng of pcDNA3.1-lhr harboring the full coding region of zebrafish $\mathrm{lhr}$ and different concentrations (50, 100, 200, 500 and 1000 ng per well) of a pcDNA3.1$f s h$ expression plasmid. The mixtures of the constructs were incubated in a total volume of $250 \mu \mathrm{L}$ serum-free medium containing $1 \mu \mathrm{L}$ Lipofectamine2000 reagent (Life Technologies) for $30 \mathrm{~min}$ before being added into each well. After $6 \mathrm{~h}$, the medium was removed and replaced with $400 \mu \mathrm{L}$ complete growth medium. For positive controls, cells were transfected with the pcDNA3.1-lh expression plasmid (1000ng per well). For negative control, a frameshift mutation was engineered on the $f s h$ beta subunit using two restriction enzymes BlpI and XhoI (New England Biolabs, Ipswich, MA, USA), generating a premature stop codon resulting in a defective Fsh. Cells were transfected with 1000 ng per well of the pcDNA3.1$f s h$-defective mutant vector in the experiments as negative control. (The mutation site of the negative control is shown in Supplementary Fig. 3 and the primers are listed in Supplementary Table 1.) After $48 \mathrm{~h}$, cells were washed with PBS and lysed by passive lysis buffer (Promega) for $15 \mathrm{~min}$. Firefly and Renilla luciferase activities were measured using the dual luciferase system (Promega) on a luminometer (Promega). Firefly luciferase activity was normalized to Renilla luciferase activity. The same method was performed to test Lh-Fshr activation, using $1000 \mathrm{ng}$ of pcDNA3.1-fsh or pcDNA3.1-fsh-defective mutant as the positive or negative control, respectively, and different concentrations $(50,100,200,500$ and 1000 ng per well) of the pcDNA3.1-lh expression plasmid as the experimental groups.

For stable transfections, a COS-7-Lhr and a COS-7Fshr stable cell line were established by following the same steps as described (Chan \& Cheng 2004). Briefly, COS-7 cells were cultured in Dulbecco's Modified Eagle's medium (Hyclone, Logan, UT, USA) supplemented with 10\% FBS and 1\% PS in $100 \mathrm{~mm}$ culture plates (Iwaki, Tokyo, Japan) before transfected with $2 \mu \mathrm{g}$ of the pcDNA3.1-lhr or pcDNA3.1-fshr plasmid. After transfection, the medium was changed to DMEM supplemented with 10\% FBS and $500 \mathrm{ng} / \mathrm{mL}$ Geneticin (G418) (Thermo Fisher Scientific) for one week to perform antibiotic selection. A concentration of $1 \mathrm{mg} / \mathrm{mL}$ G418 was employed to maintain the COS7-Lhr or COS-7-Fshr cell line. 1000ng of the pcDNA3.1lh or the pcDNA3.1-fsh plasmid expression plasmid was used as the positive control in the COS-7-Lhr or COS-7Fshr stable cell line, respectively. For negative controls, $1000 \mathrm{ng}$ per well of the pcDNA3.1-fsh-defective mutant construct was transfected in both experiments. To detect the activation of Lhr by Fsh (and Fshr by Lh), different concentrations (50, 200 and 1000 ng) of the pcDNA3.1$f s h$ (or the pcDNA3.1-lh) expression plasmid were applied to the COS-7-Lhr (or the COS-7-Fshr) cell line. Luciferase activities were measured as described previously.

\section{In vivo microinjection and luciferase assays}

To test the activation of Lhr by Fsh, fertilized AB wildtype zebrafish embryos at one-cell stage were co-injected with $50 \mathrm{ng} / \mu \mathrm{L}$ of the pCRE-Luc plasmid, $0.5 \mathrm{ng} / \mu \mathrm{L}$ of the pRL-CMV construct, $50 \mathrm{ng} / \mathrm{\mu L}$ of the pcDNA3.1-lhr and different amounts $(200 \mathrm{ng} / \mu \mathrm{L}, 500 \mathrm{ng} / \mu \mathrm{L})$ of the pcDNA3.1-fsh plasmid (Ahmed et al. 2011). For positive and negative controls, the embryos were microinjected 
with the pcDNA3.1-lh or the pcDNA3.1-fsh-defective mutant expression plasmids $(500 \mathrm{ng} / \mu \mathrm{L})$. Three nanoliters of DNA samples were microinjected into the yolk of each zygote at one-cell stage. The embryos were allowed to develop until $24 \mathrm{hpf}$ and then groups of 15 embryos were lysed in passive lysis buffer (Promega), and luciferase activities were measured as described (Alcaraz-Perez et al. 2008). Similar procedures were performed to study Lh-Fshr activation using the pcDNA3.1-fshr construct, with $500 \mathrm{ng} / \mu \mathrm{L}$ of the pcDNA3.1-fsh or pcDNA3.1-fsh-defective mutant expression plasmids as the positive control and negative control, respectively. The experimental groups were consisted of 200 or $500 \mathrm{ng} / \mathrm{\mu L}$ of the pcDNA3.1-lh expression plasmid.

\section{Statistical analysis}

The GraphPad Instat software (GraphPad Software) was utilized for all the statistical analyses. All data were presented as mean \pm s.D. Student's $t$-test and one-way ANOVA followed by Tukey's test were used for comparisons between two and more groups, respectively. And $P<0.05$ was considered statistically significant.

\section{Results}

\section{Sex ratio and fertility assessment of the $I h b ; / h r$ and fshb;fshr double knockout mutants}

The heterozygous and homozygous double knockout mutants of lhb;lhr and fshb;fshr were ascertained by sequencing. A normal ratio of males to females was found in the adult homozygous $l h b ; l h r$ mutants. However, double knockout of $f s h b ; f s h r$ led to all male offspring (Fig. 1A and $\mathrm{B})$. This result confirmed that the Fsh signaling is essential for maintaining the female status (Chu et al. 2015, Zhang et al. 2015a).

The fertility of $l h b ; l h r$ and $f s h b ; f s h r$ mutant males was assessed. No significant difference in fertilization rate was found between the homozygous males $\left(l h b^{-/-} ; l h r^{--}\right.$and $\left.f s h b^{-1-} ; f s^{-1-}\right)$ and their corresponding heterozygous controls $\left(l h b^{+-} ; l h r^{+-}\right.$and $\left.f s h b^{+-} ; f s h r^{+-}\right)$, indicating that the double mutant $l h b ; l h r$ and $f s h b ; f s h r$ males are fertile (Fig. $1 \mathrm{C}$ and D).

\section{Spermatogenesis in the $I h b ; / h r$ and $f s h b ; f s h r$ double knockout males}

To further analyze the phenotypes of the lhb;lhr and fshb;fshr double knockout males, testes of the adult
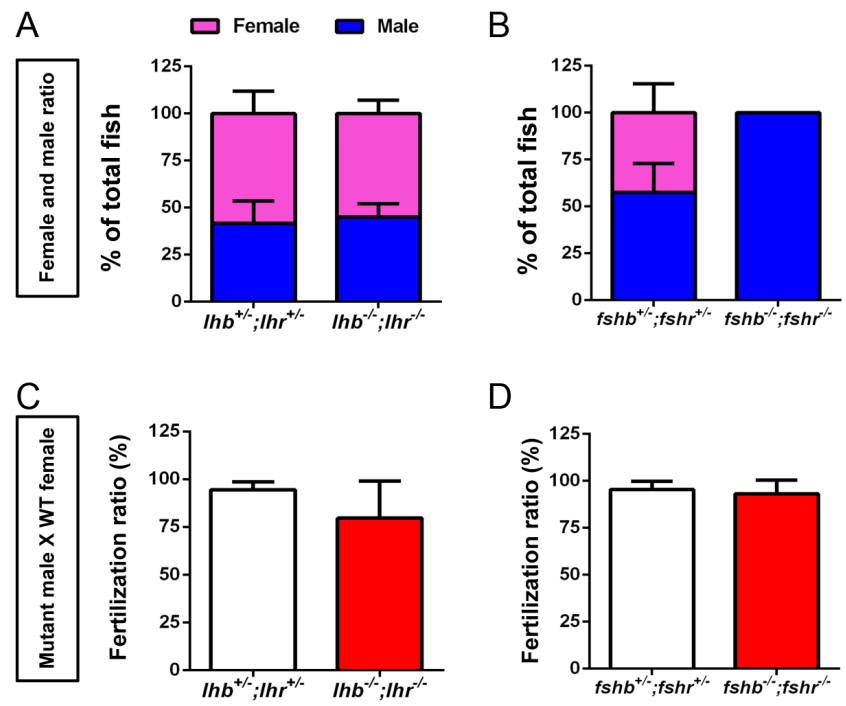

Figure 1

Sex ratio and fertility assessment of the $I h b ; / h r$ and $f s h b ; f s h r$ double mutant zebrafish at four months postfertilization. (A) The sex ratio of the $I h^{+/-;} / h^{+/-}$(no. of offspring used $=54$ ) and $/ h^{-/-} ; / h r^{-/-}$(no. of offspring used $=14$ ) zebrafish. (B) The sex ratio of the $f s h b^{+/-} ; f s h r^{+-}$(no. of offspring used $=68$ ) and $f s^{-1-} ; f s h r^{-1-}$ (no. of offspring used $=22$ ) zebrafish. (C) The fertilization ratio of control $\left(/ \mathrm{hb}^{+/-} ; / \mathrm{hr}^{+/-}\right)$and homozygous $\left(/ \mathrm{hb}^{-/-} ; / \mathrm{hr}^{-/-}\right)$ mutant male zebrafish upon crossing with wild-type females ( $n=4$ from each group of fish). (D) The fertilization ratio of control ( $f s h^{+/-} ; f s h r^{+/-}$) and homozygous ( $f s b^{---;} ; f_{\left.s h r^{--}\right)}$mutant male zebrafish upon crossing with wild-type females ( $n=3$ from each group fish). A full colour version of this figure is available at http://dx.doi.org/10.1530/JOE-17-0079.

fish were analyzed morphologically and histologically. No significant difference in the gonadosomatic index (GSI) was found between the adult homozygous double mutant males and their heterozygous controls (Fig. 2A and B). Histological analysis by H\&E staining showed that different stages of sperm cells could be found in the testes of both the $l h b ; l h r$ and fshb;fshr mutants (Fig. 2C). Normal localization of spermatocytes was also confirmed by immunostaining of PHH3, which is a marker for the metaphase of germ cells (Ladstein et al. 2010) (Fig. 2D).

The number of different stages of spermatogenic cells including spermatogonia (SG), spermatocytes (SC), spermatids (ST) and spermatozoa (SZ) were further calculated based on the H\&E staining and PHH3 immunostaining. In both the lhb;lhr- and fshb;fshrmutant males, no significant difference was found in the number of the different stages of sperm cells between the homozygotes ( $l \mathrm{hb}^{-/-} ; \mathrm{lhr^{-- }}$ and $f \mathrm{shb}^{-/-} ; f \mathrm{fhr}^{-/-}$) and the heterozygous controls $\left(l h b^{+/-} ; l h r^{+/-}\right.$and $f s h b^{+/-}$ ;fshrt-) (Fig. 2E and F). The number of SG appeared to be somewhat decreased in the $l \mathrm{hb}^{-/-} ; \mathrm{lhr} /-$ mutant group (Fig. 2E), but the difference was not statistically significant. These data demonstrated that the actions of Lh signaling 
A

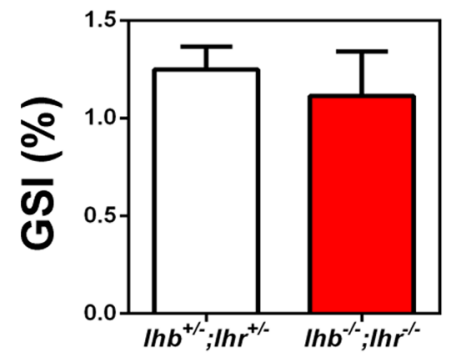

B

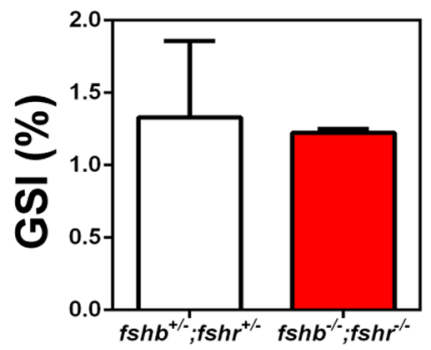

C
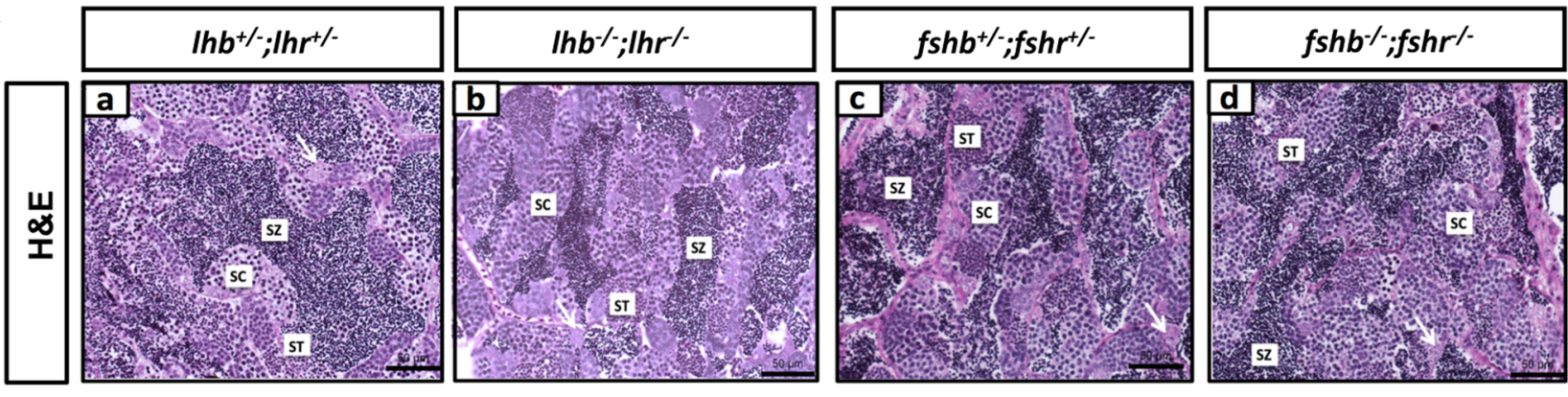

D
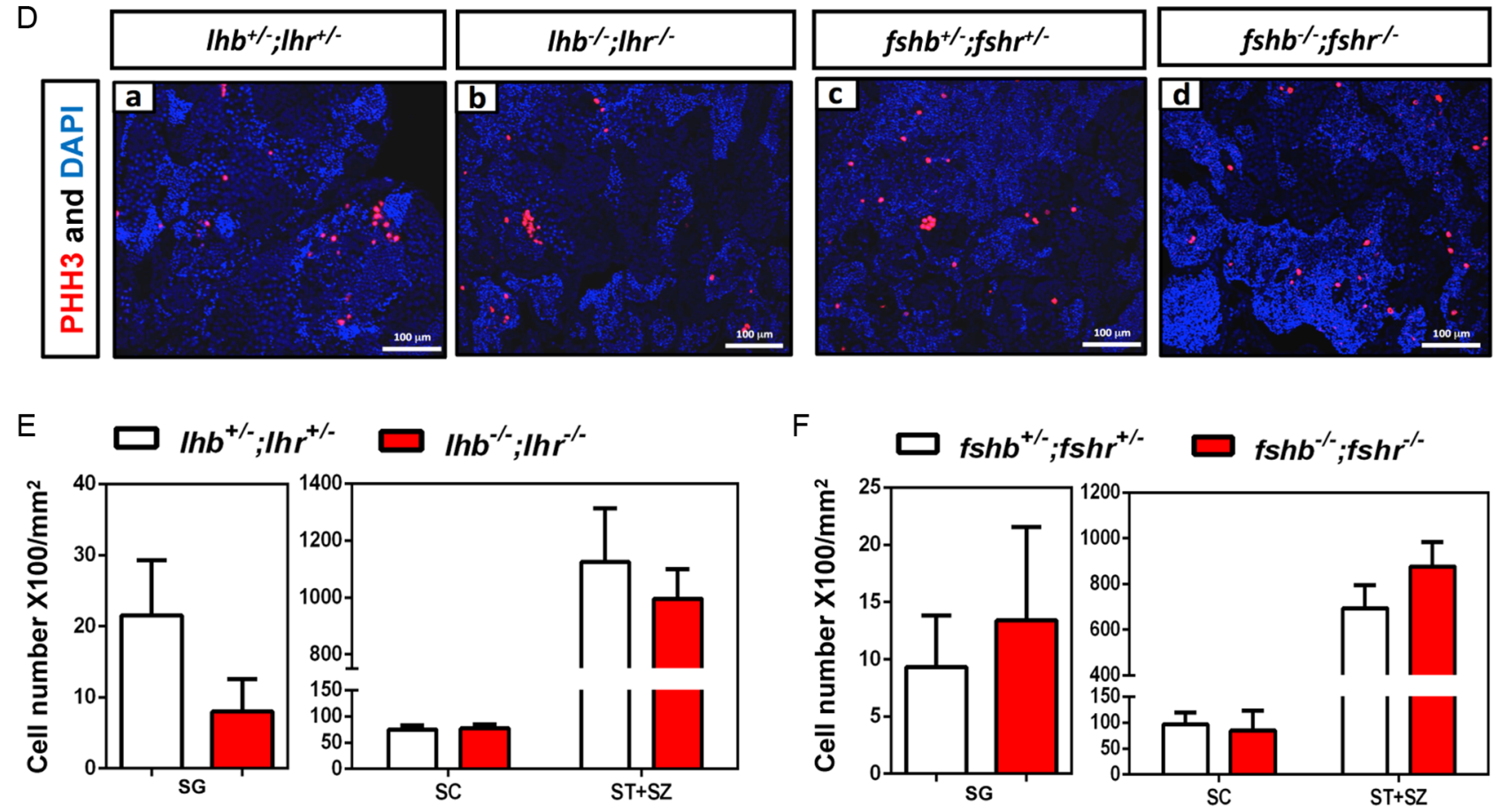

Figure 2

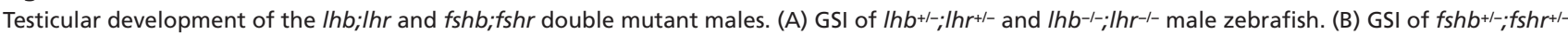

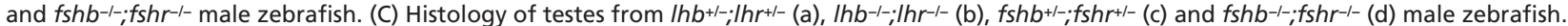

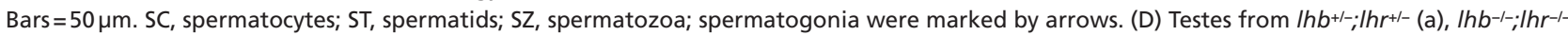
(b), fshb ${ }^{+/-} ; f_{s h r+/-}$ (c) and fshb-l-;fshr-l- (d) male zebrafish stained with PHH3 (red) and DAPI (blue). Bars $=100 \mu m$. (E) The number of the different stages

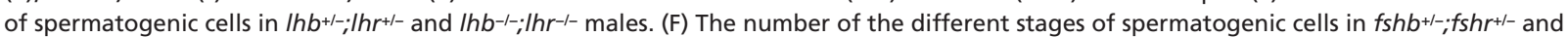

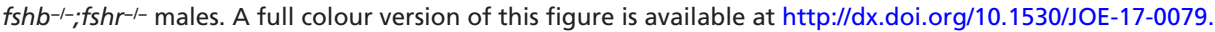


and Fsh signaling on spermatogenesis in zebrafish are highly overlapping and could functionally compensate each other.

\section{Androgen levels and gene expression profile in Ihb;/hr and fshb;fshr double knockout males}

To further assess the effects of gene knockout on testicular function, the concentration of androgens in the serum was measured by ELISA. Testosterone (T) and 11-ketotesterone (11-KT) are the two dominant androgens in zebrafish (Schulz et al. 2010). The level of 11-KT was not significantly affected in both homozygous mutants

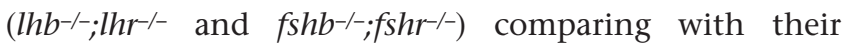
corresponding heterozygous controls $\left(\mathrm{lhb}^{+/-} ; \mathrm{lhr^{+/ }}\right.$ and $\left.f s h b^{+-} ; f s h r^{+-}\right)$. However, the level of $\mathrm{T}$ was significantly lower in the $f s^{-1-} ; f s h r^{--}$mutant than its control (Fig. 3A and $\mathrm{B})$. The expression of a number of key enzymes involved in steroidgoenesis (star, p450scc, 3b-hsd and $17 b$-hsd3) was further assessed by quantitative real-time

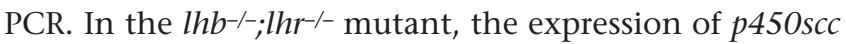
and $17 \mathrm{~b}$-hsd was significantly decreased, while that of star was increased as compared to the control. And in the $f s^{-/-} ; f s r^{-/}$mutant, the expression of all these genes was significantly decreased (Fig. 3C and D). These results suggest that the shutting down of either the Lh signaling or the Fsh signaling pathway did produce some changes on the gene expression of the steroidogenic enzymes in the testis, leading to some minor changes in the androgen levels in the mutants. However, these changes were not sufficient to alter the phenotype of the mutants, which are fully fertile morphologically, histologically and functionally. These findings lend strong support that $\mathrm{Lh}$ signaling and Fsh signaling could essentially compensate each other to regulate spermatogenesis in zebrafish.

The possibility that compensation of Lh signaling and Fsh signaling in the homozygous mutants was due to the increase in concentration of the remaining intact undisrupted gonadotropin was also considered. Thus, plasma Fsh level in the $l h b ; l h r$ mutant males and plasma Lh level in the $f s h b ; f s h r$ mutant males were also measured by ELISA. The results indicate that the level of the intact undisrupted gonadotropin remained normal in both the $l h b ; l h r$ and $f s h b ; f s h r$ mutant males (Fig. 3E and F). These data further substantiate the existence of functional redundancy between Lh signaling and Fsh signaling in zebrafish spermatogenesis.

\section{Double knockout of $/ h b$ and $f s h r$ leads to all fertile males}

Cross-activation of Fshr by Lh has been shown in zebrafish previously, but cross-activation of Lhr by Fsh has never been demonstrated before, thus prompting us to further establish the $l h b ; f s h r$ double knockout mutant line. All

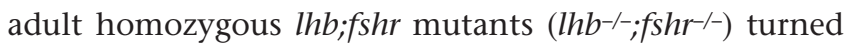
out to be all males (Fig. 4A). This result was anticipated
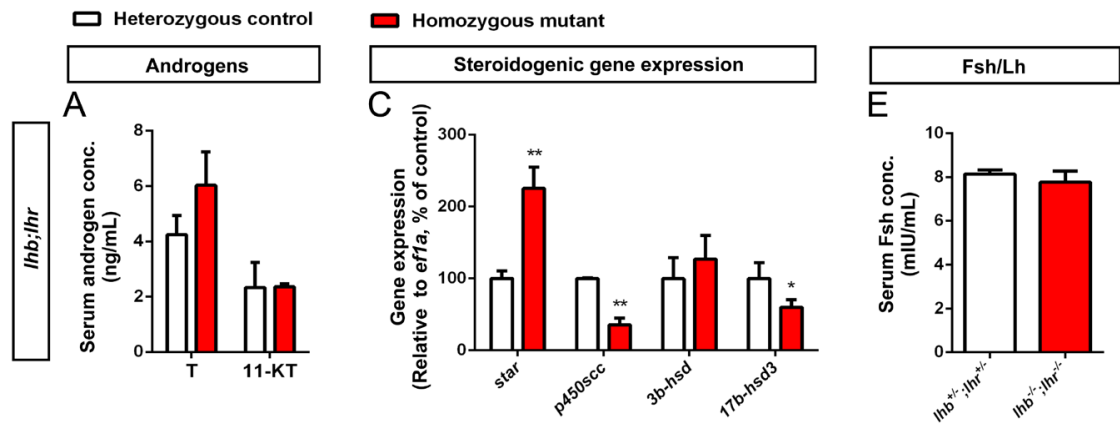

Figure 3

Serum androgen level and gene expression profile in the testes of the $/ h b ; / h r$ and $f s h b ; f s h r$ double mutant males. (A) Serum concentration of

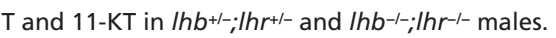
(B) Serum concentration of T and 11-KT in $\mathrm{fshb}^{+/-}$; $\mathrm{fshr}^{+/-}$and $\mathrm{fshb}^{-/-} ; \mathrm{fshr}^{-/-}$males. (C) The expression of star, p450scc, 3b-hsd and 17b-hsd3 (relative to ef1a) in the testes of $/ h^{-1 /-;} / h^{+/-}$and $/ h^{-/-} ; / h r^{-1-}$

$\mathrm{F}$
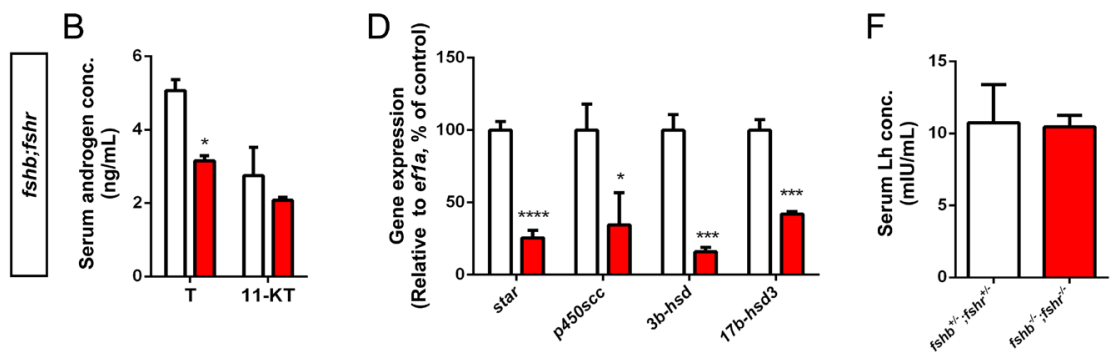

males. (D) The expression of star, p450scc, 3b-hsd and 17b-hsd3 (relative to ef1a) in the testes of $\mathrm{fsh}^{+/-} ; \mathrm{fshr}^{+/-}$and $\mathrm{fshb}^{-1-} ; \mathrm{fshr}^{-1-}$ males. (E) Serum

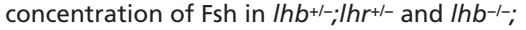
$\mathrm{Ihr}^{-1-}$ males. (F) Serum concentration of Lh in $\mathrm{fshb}$

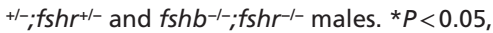

$* * P<0.01, * * * P<0.005, * * * * P<0.001$. A full colour version of this figure is available at http:// dx.doi.org/10.1530/JOE-17-0079. 


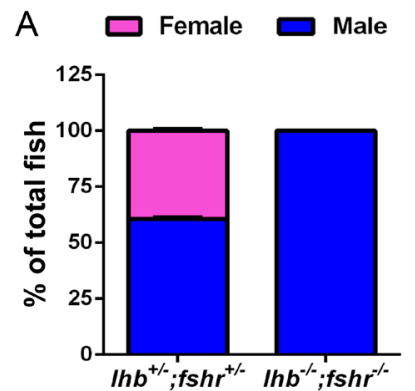

B

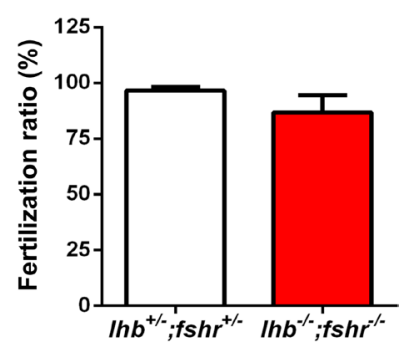

Figure 4

Sex ratio and fertility assessment of the $I h b ; / h r$ and fshb;fshr double mutant zebrafish. (A) The sex ratio of the $/ h b^{+/-;} ; s h r^{+/-}$(no. of offspring used $=55)$ and $/ \mathrm{hb}^{-1-}$;fshr-l- (no. of offspring used $=12$ ) zebrafish. (B) The fertilization ratio of control ( $\left./ \mathrm{hb}^{+/-} ; \mathrm{fshr}^{+--}\right)$and homozygous $\left(\mathrm{Ihb}^{-1-} ; \mathrm{fshr}^{-1-}\right)$ mutant male zebrafish upon crossing with wild-type females ( $n=3$ from each group of fish). A full colour version of this figure is available at http://dx.doi.org/10.1530/JOE-17-0079.

because disruption of Fsh signaling could not sustain the female phenotype. Surprisingly, however, these double mutant homozygous males were fertile, as demonstrated by mating of the homozygous $l h b ; f s h r$ double mutants

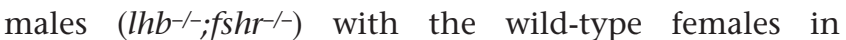
producing normal offspring. The fertilization ratio of the

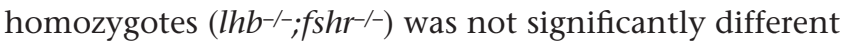

from the heterozygous control $\left(l h b^{+-} ; f s h r^{+-}\right)$, suggesting that simultaneous knockout of $l \mathrm{hb}$ and $f$ sh $\mathrm{r}$ does not affect male fertility (Fig. 4B).

\section{Spermatogenesis in the Ihb;fshr double knockout males}

Morphological and histological examinations including H\&E staining and PHH3 immunostaining were carried out on the $l h b ; f s h r$ double knockout fish. The testicular GSI value was not altered (Fig. 5A). Different stages of sperm cells (Fig. 5B), with a significant increase in SC number and a decreased number of ST plus SZ found in the testes of the homozgyous lhb;fshr mutant $\left(\mathrm{lhb}^{-/-} ; \mathrm{fshr}^{--}\right.$) (Fig. 5C). Consistent with the H\&E staining results, PHH3 immunostaining also revealed a larger amount of spermatocytes, indicating the simultaneous knockout of both $l h b$ and fshr affects the developmental transition from SC stage to later stages during spermatogenesis (Fig. 5D). These data indicate the lhb; fshr mutant males are still capable of undergoing normal spermatogenesis in zebrafish despite some slight defects in the transition of SC to later stages. These changes however were not sufficient to alter the phenotype of the mutants, which are fully fertile functionally.
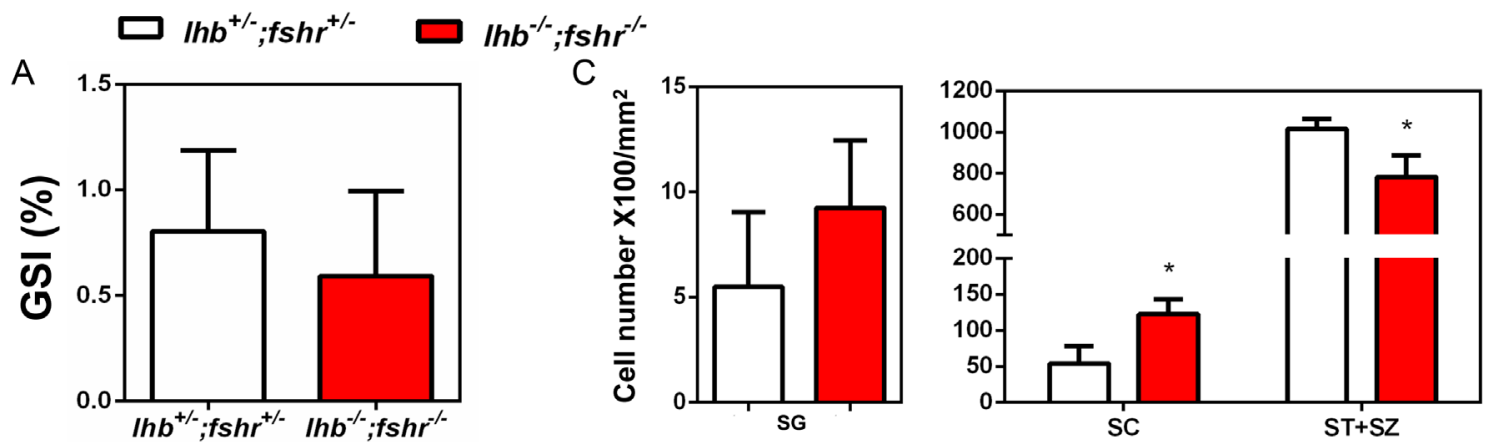

B

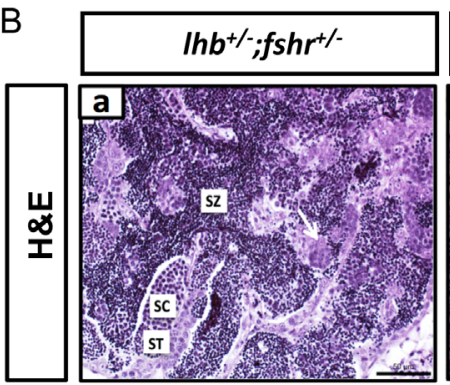

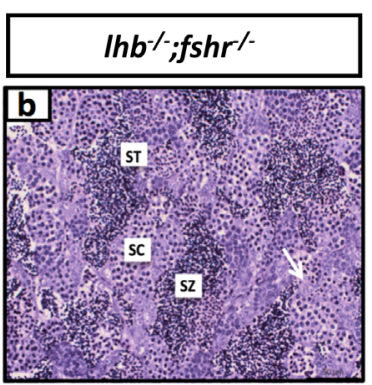

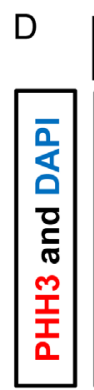

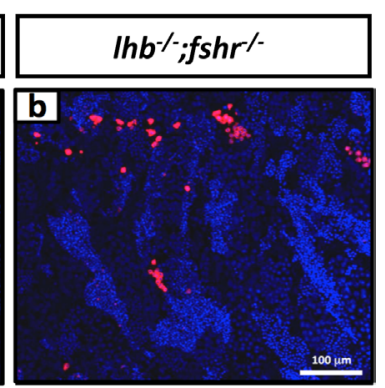

\section{Figure 5}

Testicular histology of the $I h b ; f s h r$ double mutant males. (A) GSI of $I h b^{+/-;} ; s h r^{+/-}$and $/ h b^{-1-;} ; s h r^{-/-}$male zebrafish. (B) Histology of testes from $I \mathrm{hb}^{+/-} ; \mathrm{fshr}^{+/-}$(a) and $/ \mathrm{hb}^{-1-} ; \mathrm{fshr}^{-1-}$ (b) male zebrafish. Bars $=50 \mu \mathrm{m}$. SC, spermatocytes; ST, spermatids; SZ, spermatozoa; spermatogonia were marked by

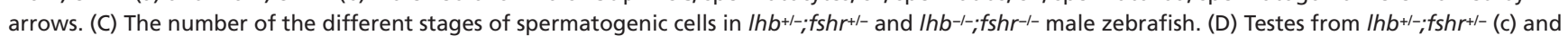
$I h^{-1-} ; f s h r^{-1-}$ (d) male zebrafish stained with PHH3 (red) and DAPI (blue). Bars $=100 \mu \mathrm{m}$. ${ }^{*} P<0.05$. A full colour version of this figure is available at http://dx.doi.org/10.1530/JOE-17-0079.

http://joe.endocrinology-journals.org DOI: 10.1530/JOE-17-0079
๑) 2017 Society for Endocrinology Printed in Great Britain
Published by Bioscientifica Ltd 


\section{Androgen levels and gene expression profile in the Ihb;fshr double knockout males}

To further characterize the phenotype of the lhb;fshr double knockout males, the concentration of both 11-KT and $\mathrm{T}$ in the serum was measured by ELISA. The level of $11-\mathrm{KT}$ in the homozygous $l h b ; f s h r$ double mutant males $\left(\mathrm{lhb}^{-/-} ; f \mathrm{fhr}^{--}\right)$is similar to the heterozygous control $\left(l h^{+-/} ; f s h r^{+-}\right)$, while the $\mathrm{T}$ level is slightly higher as compared to the heterozygous control (Fig. 6A). Expression of enzymes related to steroidogenesis in the testes was also assessed in the lhb;fshr double knockout males by real-time PCR. While the expression of p450scc and $3 b$ $h s d$ was not affected, the expression of star and $17 \mathrm{~b}$-hsd 3 was significantly decreased in the $l h b ; f s h r$ mutant males $\left(l h b^{-/} ; f s h r^{--}\right)$(Fig. 6B). These data suggest that steroidogenesis was affected in $l h b ; f s h r$ mutant males. Interestingly, a much elevated concentration of plasma Fsh was observed in the lhb;fshr mutant males (Fig. 6C). This result demonstrates that upon the deletion of Lh in zebrafish, compensation in the increased gene expression of Fsh occurs, and it is conceivable that this increased level of Fsh is exerting its action through Lhr to elicit full reproductive capacity as far as spermatogensis and male fertility are concerned.

\section{Assessment of cross-activation of Lhr by Fsh and of Fshr by Lh in zebrafish}

As indicated in the previous paragraph and in our published findings (Chu et al. 2015), an explanation of the fertile phenotype observed in the $l h b ; f s h r$ and fshb;lhr double knockout males is the existence of crossactivation between Lh signaling and Fsh signaling. Several assay systems were employed to test the crossreactivity. To explore the activation of Lhr by Fsh, a cellbased functional assay of Lhr activity was performed using $\mathrm{CHO}$ cells co-transfected with zebrafish Lhr and different concentrations of Fsh plasmids in a transient transfection assay system with the proper positive and negative controls. A dose-dependent increase in CRE promoter activity was observed after transfection with the Fsh plasmid (Fig. 7A), indicating the functional interaction of Fsh with $\mathrm{Lhr}$ to elicit the post-receptor signaling event. Meanwhile, an increased CRE promoter activity was also noted after transfection of the Fsh plasmid into a COS-7 cell line stably expressing zebrafish Lhr (Fig. 7B). These results obtained from two different cell systems demonstrate the functional activation of Lhr by Fsh. To further substantiate the occurrence of this cross-activation in an in vivo system, both $\mathrm{Lhr}$ and Fsh plasmids were microinjected into one-cell stage zebrafish embryos and CRE promoter activity was measured after $24 \mathrm{~h}$ post fertilization. The CRE promoter activity was again significantly increased upon co-injection of the Lhr and Fsh plasmids (Fig. 7C). All these results clearly demonstrate that Fsh could activate Lhr in zebrafish.

Similarly, the same three assay systems were utilized to test the activation of Fshr by Lh. Consistent with the previous finding (So et al. 2005), zebrafish Lh was capable of stimulating Fshr, resulting in a dose-dependent increase of the CRE promoter activity in the transientand stable-transfected cells as well as in the zebrafish embryos (Fig. 7D, E and F). These data confirmed the existence of Lh-Fshr activation in zebrafish. Taken together, the cross-activation of the two gonadotropins and the two gonadotropin receptors in zebrafish has been substantiated, further providing evidence for the overlapping actions of $\mathrm{Lh}$ and Fsh signaling in zebrafish spermatogenesis.

\section{Discussion}

To systematically analyze the functions of gonadotropin signaling in zebrafish reproduction, we have previously established four single mutant lines ( $l h b, l h r, f s h b$ and $f s h r)$ and three double mutant lines (lhb;fshb, lhr;fshr, $f s h b ; l h r)$ using TALENs. All the lhb, lhr, fshb and $f s h r$

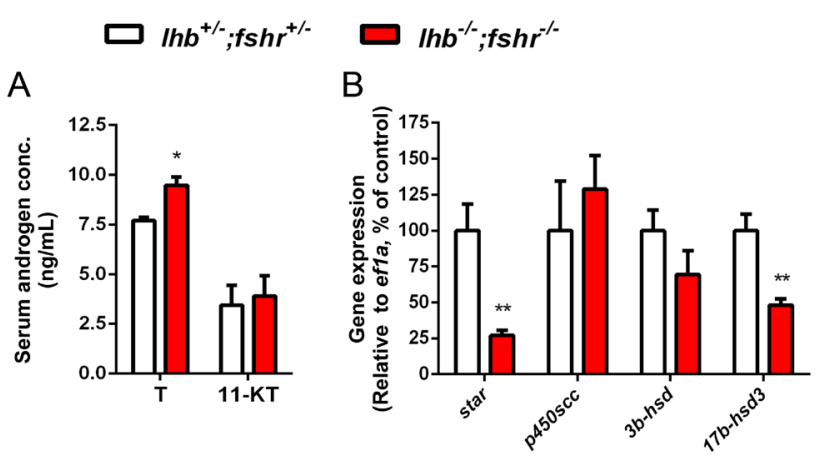

http://joe.endocrinology-journals.org DOI: 10.1530/JOE-17-0079
๑) 2017 Society for Endocrinology Printed in Great Britain

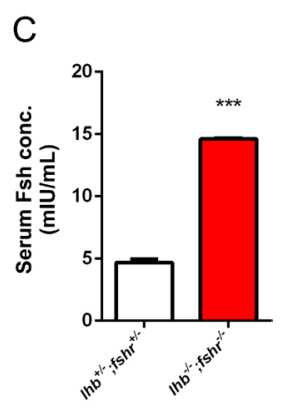

Figure 6

Serum androgen level and expression profile of key steroidogenic enzymes in the testes of the Ihb;fshr double mutant males. (A) Serum concentration of T and 11-KT in $/ \mathrm{hb}^{+/-} ; \mathrm{fshr}^{+/-}$and Ihb-l-; fshr-l- males. (B) The expression of star, p450scc, 3b-hsd and 17b-hsd3 (relative to ef1a) in

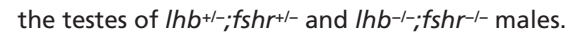
(C) Serum concentration of Fsh in $/ h^{+/-;} ; \mathrm{fshr}^{+/-}$ and $/ h^{-l-} ;$ fshr-l- male zebrafish. ${ }^{\star} P<0.05$, $* * P<0.01, * * * P<0.005$. A full colour version of this figure is available at http://dx.doi. org/10.1530/JOE-17-0079. 

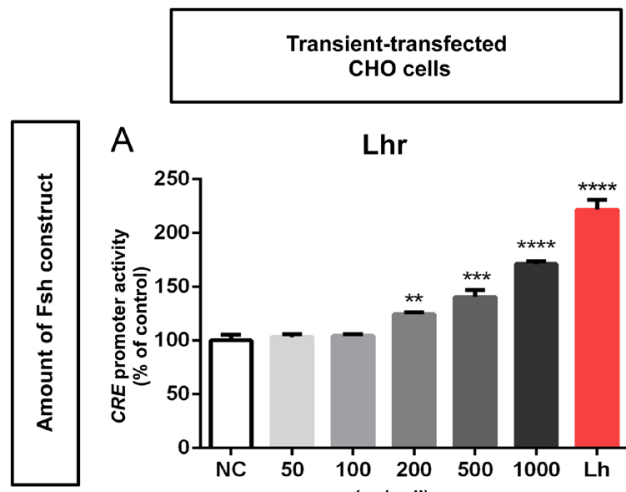

A

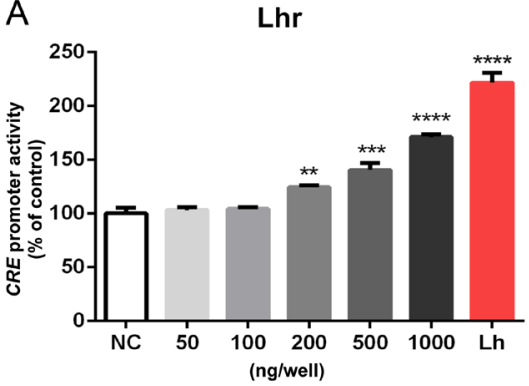

D

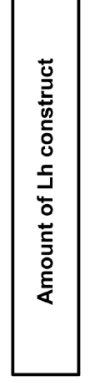$$
\text { }
$$

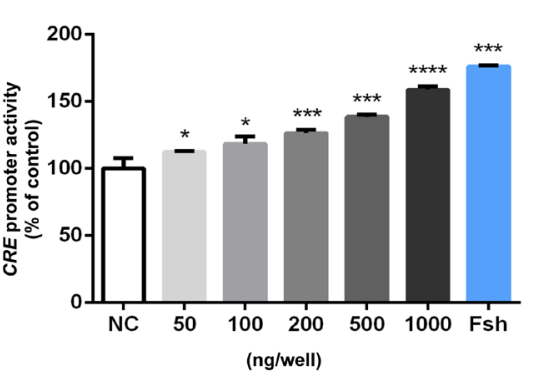

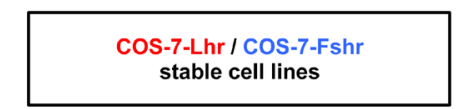

B

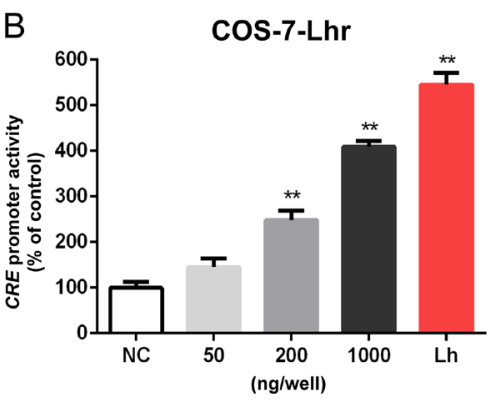

E

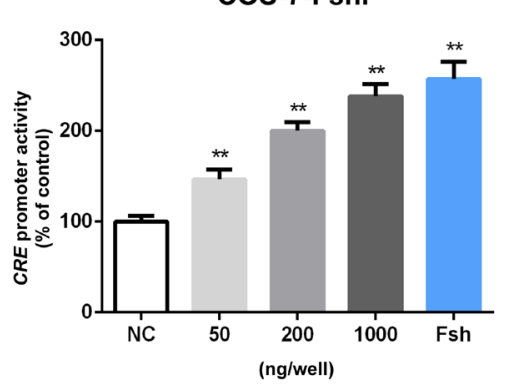

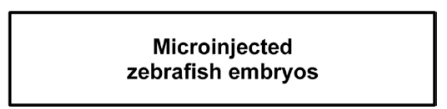

C Lhr

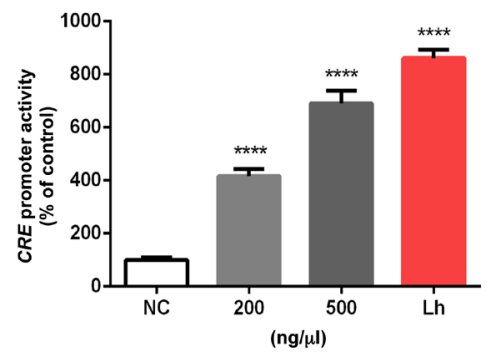

F

Fshr

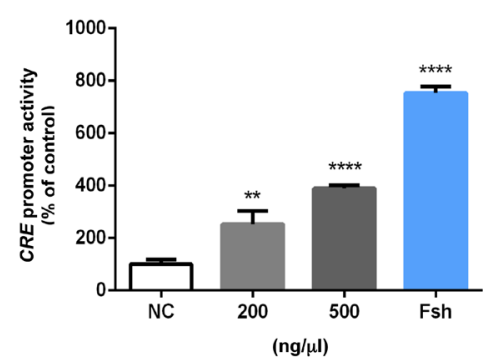

Figure 7

Assessment of the cross-activation of the two gonadotropins and the two gonadotropin receptors in zebrafish. Different amounts of a zebrafish fsh expression plasmid were transfected into CHO cells (A), a COS-7-Lhr stable cell line (B) or microinjected into zebrafish embryos (C). The zebrafish Ih expression plasmid was used as the positive control in Panels (A) to (C). Similarly, different amounts of a zebrafish $/ \mathrm{h}$ expression plasmid were transfected into $\mathrm{CHO}$ cells (D), a COS-7-Fshr stable cell line (E) or microinjected into zebrafish embryos (F). The zebrafish fsh expression plasmid was used as the positive control in Panels (D) to (F). An expression plasmid harboring the defective mutant zebrafish fsh was used as the negative control in all these assays. ${ }^{*} P<0.05, * * P<0.01, * * * P<0.005, * * * * P<0.001$, compared to the negative control group. A full colour version of this figure is available at http://dx.doi.org/10.1530/JOE-17-0079.

single mutants and the fshb;lhr double mutant male fish are fertile and spermatogenesis remains intact. On the other hand, however, both the $l h b ; f s h b$ and $l h r ; f s h r$ double mutant male fish are infertile due to impaired spermatogenesis (Chu et al. 2014, 2015). All these findings led us to conclude that gonadotropin signaling is essential for spermatogenesis and that Lh can also act through Fshr in a non-canonical manner. In the present study, we have further dissected the actions of gonadotropin signaling in spermatogenesis using three additional double mutant lines (lhb;lhr, fshb;fshr and $l h b ; f s h r)$. There are two major findings from the present study. First, both $l h b ; l h r$ and $f s h b ; f s h r$ mutant males are fertile, and this provides unequivocal evidence to the highly overlapping actions of Lh signaling and Fsh signaling in regulating spermatogenesis in zebrafish. Second, analysis of the fertile phenotype in the $l h b ; f s h r$ mutant males revealed the cross-activation of Lhr by Fsh in zebrafish. The cross-activation of Lhr by Fsh and of Fshr by Lh in zebrafish was also substantiated by a number of transfection and microinjection assays. Based on these genetic and biochemical evidence, we propose a model on the role of gonadotropin signaling in regulating spermatogenesis in zebrafish (Figs 8 and 9).

We have noticed the normal sex ratio between males and females in the adult lhb;lhr mutants, but all adult $f s h b ; f s h r$ and $l h b ; f s h r$ mutants differentiated into males. This result is in fact consistent with our data and that of others on the single mutant (lhb, lhr, fshb and $f s h r$ ) and double mutant (lhb;fshb, lhr;fshr, fshb;lhr) zebrafish (Chu et al. 2014, 2015, Zhang et al. 2015a,b) as well as a fshr mutant medaka (Murozumi et al. 2014), that disruption of Fsh signaling could lead to the failure of follicle activation and possibly sex reversal from females to males. All these findings clearly demonstrate that Fsh signaling is pivotal for maintaining the female status in zebrafish. However, it might be worth noting that testicular differentiation in zebrafish goes through an 'ovarian' morphogenic stage, which might therefore be expected to be Fsh independent, 


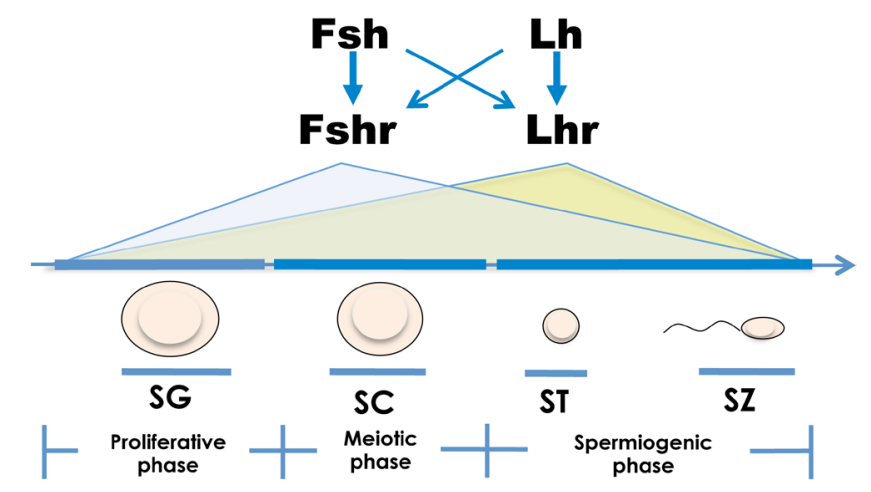

Figure 8

A proposed model of gonadotropin signaling on spermatogenesis in zebrafish. Lh signaling and Fsh signaling can functionally compensate each other in spermatogenesis. The two ligands $L h$ and Fsh are capable of activating both receptors. SC, spermatocytes; SG, spermatogonia; ST, spermatids; SZ, spermatozoa. A full colour version of this figure is available at http://dx.doi.org/10.1530/JOE-17-0079.

even if further ovarian differentiation is dependent on Fsh (Liew \& Orban 2014).

Both the $l h b ; l h r$ and $f s h b ; f s h r$ double mutant males are fertile and possess normal GSI and spermatogenesis. These findings are concordant with our recent studies that all $l h b, l h r, f s h b$ and $f s h r$ single mutant male fish are fertile. More interestingly, we found in the present study that the plasma Fsh level in the $l h b ; l h r$ double mutant male and the plasma Lh level in fshb;fshr mutant male were not altered as compared to the controls, providing further support that Fsh signaling or Lh signaling alone is sufficient to maintain normal androgen production and spermatogenesis in zebrafish. This conclusion is also supported by recent studies on the assessment of the action
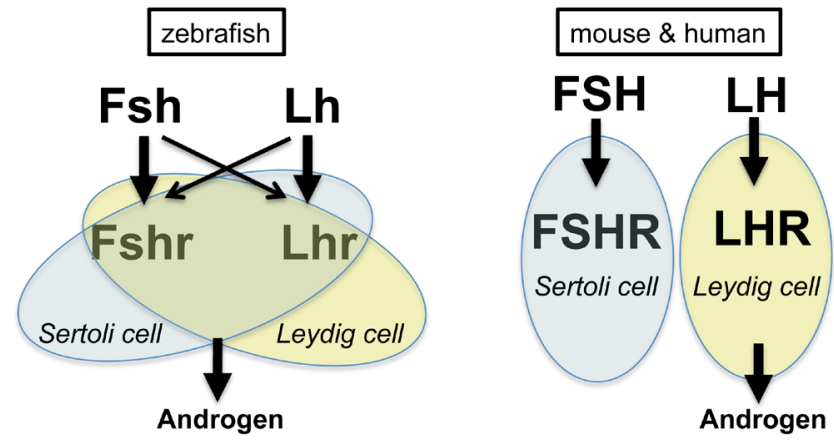

\section{Figure 9}

Comparison of gonadotropin signaling and receptor localization in zebrafish with mouse and human. In zebrafish, the interaction of Lh and Fsh with their receptors is promiscuous. Fshr and Lhr exist on both Leydig cells and Sertoli cells to induce androgen production. Although in mouse and human, LH activates LHR on Leydig cells for androgen production independent of the specific interaction of FSH with FSHR on Sertoli cells. A full colour version of this figure is available at http://dx.doi.org/10.1530/ JOE-17-0079. of both Lh and Fsh on the fish testis. In zebrafish, both Lh and Fsh could stimulate androgen production in vitro and in vivo (Garcia-Lopez et al. 2010). In rainbow trout, one-third of the regulated transcripts could be similarly regulated by both Fsh and Lh in the testis (Sambroni et al. 2013). In big contrast to zebrafish, studies on mutations in human and knockout mice showed the specific actions of both FSH and LH signaling on spermatogenesis, in that FSH regulates Sertoli cell activity to increase the number of spermatogonia and enhances their entry into meiosis (Abel et al. 2000, Siegel et al. 2013), although the importance of FSH signaling in spermatogenesis of mice and human remains debatable; while LH regulates Leydig cell sex steroid production, which allows the completion of meiosis and spermiogenesis (Kumar 2005, Ramaswamy \& Weinbauer 2014). Such difference between zebrafish and mammals could be partially explained by the different tissue expression patterns of the two gonadotropin receptors. In mammals, FSHR and LHR are exclusively expressed in Sertoli cells and Leydig cells, respectively, but these two receptors are co-expressed in both Sertoli cells and Leydig cells in several fish species including zebrafish (Oba et al. 2001, Garcia-Lopez et al. 2010) (Fig. 9). Our study also raised an interesting question: if either Fsh signaling or Lh signaling alone is sufficient to maintain normal spermatogenesis in zebrafish, why could these two gonadotropin systems be retained in the fish testis during evolution? Noting that the divergent actions of both Lh signaling and Fsh signaling on ovarian functions are conserved from zebrafish to human (Kumar et al. 1997, Kumar 2005, Kumar \& Sait 2011, Ogiwara et al. 2013, Murozumi et al. 2014), it is conceivable that the two gonadotropin systems might have evolved primarily to fulfill the needs of ovarian development. Different from that in the ovary, the specialization of Lh signaling and Fsh signaling in the testis occurred gradually during evolution and took a different course in different vertebrates. For example, in some mammals including primates and mice, LH signaling is the dominant gonadotropin system in affecting spermatogenesis; while in other mammals such as hamsters, spermatogenesis is predominantly dependent on FSH signaling (Ramaswamy \& Weinbauer 2014, Huhtaniemi 2015).

One of the most striking findings of the present study is the phenotype of the $l h b ; f s h r$ double mutant zebrafish. It has been reported in zebrafish that Fshr could crossreact with Lh but Lhr could not cross-react with Fsh (So et al. 2005). Therefore, initially, we expected that the double knockout of both $l h b$ and fshr would disrupt both Lh and Fsh signaling in zebrafish, leading to an infertile

Published by Bioscientifica Ltd 
phenotype similar to that observed in the $l h b ; f s h b$ and $l h r ; f s h r$ double mutants. Surprisingly, we found that all the $l h b ; f s h r$ double adult mutant males are fully fertile. GSI and the ability to produce viable gametes were not significantly affected, demonstrating that the simultaneous double knockout of both $l h b$ and $f s h r$ did not affect male reproduction. This phenotype could not be explained by the constitutive activity of Lhr, because such constitutive activity of either Lhr or Fshr is not capable of supporting full spermatogenesis in zebrafish as demonstrated by the infertile phenotype of the lhb; $f$ shb double mutant males (Chu et al. 2015). The other explanation is that Fsh exerts its actions by cross-activating Lhr to maintain full functional spermatogenesis in the lhb;fshr double mutants. We have substantiated this using three different assay systems. Our results have clearly demonstrated for the first time in zebrafish that Lhr could indeed be crossactivated by Fsh. These strong genetic and biochemical evidence demonstrated unequivocally that Fsh could regulate spermatogenesis through $\mathrm{Lhr}$ in the absence of Lh and Fshr in males. The dramatically increased Fsh level in the plasma of the lhb; fshr double mutant males could be understood in terms of the attempt by the organism to correct for the genetic defect by upregulating Fsh expression in order to exert a bigger effect in activating Lhr. We have also confirmed the activation of Fshr by Lh using the same assay systems. It thus appears that the interaction of gonadotropins and their receptors in zebrafish is highly promiscuous in that Lh and Fsh are capable of activating both receptors. Compared to the high specificity of ligand-receptor interaction in mammals, our genetic studies in zebrafish clearly demonstrate this much less refinement in ligand-receptor specificity in fish. The physiological significance of this difference is not fully known, but we hypothesize that this could be related to the duration of spermatogenesis. Sperm maturation needs a much longer time in mammals than that in fish (Nobrega et al. 2009). In zebrafish, it takes around 6 days for meiosis plus spermiogenesis (Leal et al. 2009), while in mice and rats, the time required is over 30 and 50 days, respectively (Franca et al. 1998). To guarantee offspring quality, the functions of gonadotropin signaling are more specific in spermatogenesis in mammals, and this entails a highly fine-tuned testicular development process associated with low reproductive efficiency as a price. This evolution of gonadotropins and their receptors represents a prominent example of the co-evolution of ligandreceptor interaction.

In summary, we have established three double knockout zebrafish mutant lines (lhb;lhr, fshb;fshr and $l h b ; f s h r)$ in the present study. Analysis of these mutants led us to propose a more comprehensive model on gonadotropin signaling in spermatogenesis of zebrafish. Apart from illustrating the complexity of gonadotropin signaling in fish spermatogenesis, the information obtained from the present genetic analysis also contributes toward a fuller understanding of the evolution of gonadotropin signaling in vertebrates.

\section{Supplementary data}

This is linked to the online version of the paper at http://dx.doi.org/10.1530/ JOE-17-0079.

\section{Declaration of interest}

The authors declare that there is no conflict of interest that could be perceived as prejudicing the impartiality of the research reported.

\section{Funding}

This project is supported by the General Research Fund (CUHK 14103014) of the Hong Kong Research Grants Council (RGC), the National Natural Science Foundation of China (31601205 and 31560334), and the Scientific Research Foundation of the higher education institutions of Gansu Province, China (2014B-17).

\section{References}

Abel MH, Wootton AN, Wilkins V, Huhtaniemi I, Knight PG \& Charlton HM 2000 The effect of a null mutation in the folliclestimulating hormone receptor gene on mouse reproduction. Endocrinology 141 1795-1803. (doi:10.1210/endo.141.5.7456)

Ahmed AS, Xiong F, Pang SC, He MD, Waters MJ, Zhu ZY \& Sun YH 2011 Activation of GH signaling and GH-independent stimulation of growth in zebrafish by introduction of a constitutively activated GHR construct. Transgenic Research 20 557-567. (doi:10.1007/s11248-0109439-9)

Alcaraz-Perez F, Mulero V \& Cayuela ML 2008 Application of the dual-luciferase reporter assay to the analysis of promoter activity in Zebrafish embryos. BMC Biotechnology 8 81. (doi:10.1186/ 1472-6750-8-81)

Bogerd J, Granneman JC, Schulz RW \& Vischer HF 2005 Fish FSH receptors bind $\mathrm{LH}$ : how to make the human $\mathrm{FSH}$ receptor to be more fishy? General and Comparative Endocrinology 142 34-43. (doi:10.1016/j.ygcen.2004.12.008)

Cahoreau C, Klett D \& Combarnous Y 2015 Structure-function relationships of glycoprotein hormones and their subunits' ancestors. Frontiers in Endocrinology 6 26. (doi:10.3389/fendo.2015.00026)

Camp TA, Rahal JO \& Mayo KE 1991 Cellular localization and hormonal regulation of follicle-stimulating hormone and luteinizing hormone receptor messenger RNAs in the rat ovary. Molecular Endocrinology 5 1405-1417. (doi:10.1210/mend-5-10-1405)

Chakraborty P \& Roy SK 2015 Expression of FSH receptor in the hamster ovary during perinatal development. Molecular and Cellular Endocrinology 400 41-47. (doi:10.1016/j.mce.2014.11.014)

Chan CB \& Cheng CH 2004 Identification and functional characterization of two alternatively spliced growth hormone 
secretagogue receptor transcripts from the pituitary of black seabream Acanthopagrus schlegeli. Molecular and Cellular Endocrinology 214 81-95. (doi:10.1016/j.mce.2003.11.020)

Chang N, Sun C, Gao L, Zhu D, Xu X, Zhu X, Xiong JW \& Xi JJ 2013 Genome editing with RNA-guided Cas9 nuclease in zebrafish embryos. Cell Research 23 465-472. (doi:10.1038/cr.2013.45)

Chu L, Li J, Liu Y, Hu W \& Cheng CH 2014 Targeted gene disruption in zebrafish reveals noncanonical functions of LH signaling in reproduction. Molecular Endocrinology 28 1785-1795. (doi:10.1210/ me.2014-1061)

Chu L, Li J, Liu Y \& Cheng CH 2015 Gonadotropin signaling in zebrafish ovary and testis development: insights from gene knockout study. Molecular Endocrinology 29 1743-1758. (doi:10.1210/me.2015-1126)

Fan QR \& Hendrickson WA 2005 Structure of human follicle-stimulating hormone in complex with its receptor. Nature 433 269-277. (doi:10.1038/nature03206)

Franca LR, Ogawa T, Avarbock MR, Brinster RL \& Russell LD 1998 Germ cell genotype controls cell cycle during spermatogenesis in the rat. Biology of Reproduction 59 1371-1377. (doi:10.1095/ biolreprod59.6.1371)

Garcia-Lopez A, de Jonge H, Nobrega RH, de Waal PP, van Dijk W, Hemrika W, Taranger GL, Bogerd J \& Schulz RW 2010 Studies in zebrafish reveal unusual cellular expression patterns of gonadotropin receptor messenger ribonucleic acids in the testis and unexpected functional differentiation of the gonadotropins. Endocrinology $\mathbf{1 5 1}$ 2349-2360. (doi:10.1210/en.2009-1227)

Huang P, Xiao A, Zhou MG, Zhu ZY, Lin S \& Zhang B 2011 Heritable gene targeting in zebrafish using customized TALENs. Nature Biotechnology 29 699-700. (doi:10.1038/nbt.1939)

Huhtaniemi I 2015 A short evolutionary history of FSH-stimulated spermatogenesis. Hormones 14 468-478. (doi:10.14310/horm.2002.1632)

Huhtaniemi IT \& Themmen AP 2005 Mutations in human gonadotropin and gonadotropin-receptor genes. Endocrine 26 207-217. (doi:10.1385/ENDO:26:3:207)

Hwang WY, Fu YF, Reyon D, Maeder ML, Tsai SQ, Sander JD, Peterson RT, Yeh JRJ \& Joung JK 2013 Efficient genome editing in zebrafish using a CRISPR-Cas system. Nature Biotechnology 31 227-229. (doi:10.1038/ nbt.2501)

Kumar TR 2005 Gonadotropin gene targeting and biological implications. Endocrine 26 227-233. (doi:10.1385/ENDO:26:3:227)

Kumar P \& Sait SF 2011 Luteinizing hormone and its dilemma in ovulation induction. Journal of Human Reproductive Sciences 4 2-7. (doi:10.4103/0974-1208.82351)

Kumar TR, Wang Y, Lu NF \& Matzuk MM 1997 Follicle stimulating hormone is required for ovarian follicle maturation but not male fertility. Nature Genetics 15 201-204. (doi:10.1038/ng0297-201)

Ladstein RG, Bachmann IM, Straume O \& Akslen LA 2010 Ki-67 expression is superior to mitotic count and novel proliferation markers PHH3, MCM4 and mitosin as a prognostic factor in thick cutaneous melanoma. BMC Cancer 10 140-155. (doi:10.1186/ 1471-2407-10-140)

Leal MC, Cardoso ER, Nobrega RH, Batlouni SR, Bogerd J, Franca LR \& Schulz RW 2009 Histological and stereological evaluation of zebrafish (Danio rerio) spermatogenesis with an emphasis on spermatogonial generations. Biology of Reproduction 81 177-187. (doi:10.1095/ biolreprod.109.076299)

Levavi-Sivan B, Bogerd J, Mananos EL, Gomez A \& Lareyre JJ 2010 Perspectives on fish gonadotropins and their receptors. General and Comparative Endocrinology 165 412-437. (doi:10.1016/j. ygcen.2009.07.019)

Li J, Chu L, Sun X, Liu Y \& Cheng CH 2015 IGFs mediate the action of LH on oocyte maturation in zebrafish. Molecular Endocrinology 29 373-383. (doi:10.1210/me.2014-1218)

Liew WC \& Orban L 2014 Zebrafish sex: a complicated affair. Briefings in Functional Genomics 13 172-187. (doi:10.1093/bfgp/elt041)
Liu Y, Luo D, Zhao H, Zhu Z, Hu W \& Cheng CH 2013 Inheritable and precise large genomic deletions of non-coding RNA genes in zebrafish using TALENs. PLOS ONE 8 e76387. (doi:10.1371/journal. pone.0076387)

Liu Y, Luo D, Lei Y, Hu W, Zhao H \& Cheng CH 2014 A highly effective TALEN-mediated approach for targeted gene disruption in Xenopus tropicalis and zebrafish. Methods 69 58-66. (doi:10.1016/j. ymeth.2014.02.011)

Mandarim-de-Lacerda CA 2003 Stereological tools in biomedical research. Anais da Academia Brasileira de Ciências 75 469-486. (doi:10.1590/ s0001-37652003000400006)

Menon KM \& Menon B 2012 Structure, function and regulation of gonadotropin receptors - a perspective. Molecular and Cellular Endocrinology 356 88-97. (doi:10.1016/j.mce.2012.01.021)

Moyle WR, Campbell RK, Myers RV, Bernard MP, Han Y \& Wang X 1994 Co-evolution of ligand-receptor pairs. Nature 368 251-255. (doi:10.1038/368251a0)

Murozumi N, Nakashima R, Hirai T, Kamei Y, Ishikawa-Fujiwara T, Todo T \& Kitano T 2014 Loss of follicle-stimulating hormone receptor function causes masculinization and suppression of ovarian development in genetically female medaka. Endocrinology $\mathbf{1 5 5}$ 3136-3145. (doi:10.1210/en.2013-2060)

Nobrega RH, Batlouni SR \& Franca LR 2009 An overview of functional and stereological evaluation of spermatogenesis and germ cell transplantation in fish. Fish Physiology and Biochemistry 35 197-206. (doi:10.1007/s10695-008-9252-z)

Nozaki M 2013 Hypothalamic-pituitary-gonadal endocrine system in the hagfish. Frontiers in Endocrinology 4 200. (doi:10.3389/ fendo.2013.00200)

Oba Y, Hirai T, Yoshiura Y, Kobayashi T \& Nagahama Y 2001 Fish gonadotropin and thyrotropin receptors: the evolution of glycoprotein hormone receptors in vertebrates. Comparative Biochemistry and Physiology Part B: Biochemistry and Molecular Biology 129 441-448. (doi:10.1016/S1096-4959(01)00374-8)

Ogiwara K, Fujimori C, Rajapakse S \& Takahashi T 2013 Characterization of luteinizing hormone and luteinizing hormone receptor and their indispensable role in the ovulatory process of the medaka. PLOS ONE 8 e54482. (doi:10.1371/journal.pone.0054482)

Pedroso GL, Hammes TO, Escobar TD, Fracasso LB, Forgiarini LF \& da Silveira TR 2012 Blood collection for biochemical analysis in adult zebrafish. Journal of Visualized Experiments $\mathbf{6 3}$ e3865. (doi:10.3791/3865)

Pudney J 1995 Spermatogenesis in nonmammalian vertebrates. Microscopy Research and Technique 32 459-497. (doi:10.1002/ jemt.1070320602)

Ramaswamy S \& Weinbauer GF 2014 Endocrine control of spermatogenesis: role of FSH and LH/testosterone. Spermatogenesis 4 e996025. (doi:10.1080/21565562.2014.996025)

Sambroni E, Le Gac F, Breton B \& Lareyre JJ 2007 Functional specificity of the rainbow trout (Oncorhynchus mykiss) gonadotropin receptors as assayed in a mammalian cell line. Journal of Endocrinology 195 213-228. (doi:10.1677/JOE-06-0122)

Sambroni E, Rolland AD, Lareyre JJ \& Le Gac F 2013 Fsh and Lh have common and distinct effects on gene expression in rainbow trout testis. Journal of Molecular Endocrinology 50 1-18. (doi:10.1530/JME-12-0197)

Schulz RW, de Franca LR, Lareyre JJ, Le Gac F, Chiarini-Garcia H, Nobrega RH \& Miura T 2010 Spermatogenesis in fish. General and Comparative Endocrinology 165 390-411. (doi:10.1016/j. ygcen.2009.02.013)

Siegel ET, Kim HG, Nishimoto HK \& Layman LC 2013 The molecular basis of impaired follicle-stimulating hormone action: evidence from human mutations and mouse models. Reproductive Sciences 20 211-233. (doi:10.1177/1933719112461184)

So WK, Kwok HF \& Ge W 2005 Zebrafish gonadotropins and their receptors: II. Cloning and characterization of zebrafish follicle- http://joe.endocrinology-journals.org

DOI: $10.1530 / J O E-17-0079$
(C) 2017 Society for Endocrinology Printed in Great Britain
Published by Bioscientifica Ltd 
stimulating hormone and luteinizing hormone subunits their spatial-temporal expression patterns and receptor specificity. Biology of Reproduction 72 1382-1396. (doi:10.1095/biolreprod.104.038216)

Sower SA, Freamat M \& Kavanaugh SI 2009 The origins of the vertebrate hypothalamic-pituitary-gonadal (HPG) and hypothalamic-pituitarythyroid (HPT) endocrine systems: new insights from lampreys. General and Comparative Endocrinology 161 20-29. (doi:10.1016/j. ygcen.2008.11.023)

Themmen APN \& Huhtaniemi IT 2000 Mutations of gonadotropins and gonadotropin receptors: elucidating the physiology and pathophysiology of pituitary-gonadal function. Endocrine Reviews 21 551-583. (doi:10.1210/edrv.21.5.0409)

Uchida K, Moriyama S, Chiba H, Shimotani T, Honda K, Miki M, Takahashi A, Sower SA \& Nozaki M 2010 Evolutionary origin of a functional gonadotropin in the pituitary of the most primitive vertebrate, hagfish. PNAS 107 15832-15837. (doi:10.1073/pnas.1002208107)

Vischer HF, Granneman JCM, Linskens MHK, Schulz RW \& Bogerd J 2003 Both recombinant African catfish LH and FSH are able to activate the African catfish FSH receptor. Journal of Molecular Endocrinology 31 133-140. (doi:10.1677/jme.0.0310133)

Wei SC, Gong ZD, Zhao HW, Liang HQ, Lai LJ \& Deng YY 2016 Equine chorionic gonadotropin influence on sheep oocyte in vitro maturation, apoptosis, and follicle-stimulating hormone receptor and luteinizing hormone receptor expression. Genetics and Molecular Research 15 1-13. (doi:10.4238/gmr15049162)

Yan L, Swanson P \& Dickhoff WW 1992 A two-receptor model for salmon gonadotropins (GTH I and GTH II). Biology of Reproduction 47 418-427. (doi:10.1095/biolreprod47.3.418)

Zhang ZW, Lau SW, Zhang LL \& Ge W 2015a Disruption of zebrafish follicle-stimulating hormone receptor (fshr) but not luteinizing hormone receptor (lhcgr) gene by TALEN leads to failed follicle activation in females followed by sexual reversal to males. Endocrinology 156 3747-3762. (doi:10.1210/en.2015-1039)

Zhang ZW, Zhu B \& Ge W 2015b Genetic analysis of zebrafish gonadotropin (FSH and LH) functions by TALEN-mediated gene disruption. Molecular Endocrinology 29 76-98. (doi:10.1210/me.2014-1256)

Received in final form 25 May 2017

Accepted 9 June 2017

Accepted Preprint published online 12 June 2017
๑) 2017 Society for Endocrinology Printed in Great Britain
Published by Bioscientifica Ltd 